\title{
Leaf size and leaf display of thirty-eight tropical tree species
}

\author{
Lourens Poorter · Danaë M. A. Rozendaal
}

Received: 3 August 2007 / Accepted: 4 August 2008 / Published online: 22 August 2008

(C) The Author(s) 2008. This article is published with open access at Springerlink.com

\begin{abstract}
Trees forage for light through optimal leaf display. Effective leaf display is determined by metamer traits (i.e., the internode, petiole, and corresponding leaf), and thus these traits strongly co-determine carbon gain and as a result competitive advantage in a light-limited environment. We examined 11 metamer traits of sun and shade trees of 38 coexisting moist forest tree species and determined the relative strengths of intra- and interspecific variation. Species-specific metamer traits were related to two variables that represent important life history variation; the regeneration light requirements and average leaf size of the species. Metamer traits varied strongly across species and, in contrast to our expectation, showed only modest changes in response to light. Intra- and interspecific responses to
\end{abstract}

Communicated by Nina Buchmann.

Electronic supplementary material The online version of this article (doi:10.1007/s00442-008-1131-x) contains supplementary material, which is available to authorized users.

L. Poorter $(\square)$

Forest Ecology and Forest Management Group, Center for Ecosystem Studies, Wageningen University,

P.O. Box 47, 6700 AA Wageningen, The Netherlands

e-mail: lourens.poorter@wur.nl

L. Poorter · D. M. A. Rozendaal

Instituto Boliviano de Investigación Forestal,

P.O. Box 6204, Santa Cruz, Bolivia

L. Poorter

Resource Ecology Group, Center for Ecosystem Studies,

Wageningen University, Wageningen, The Netherlands

\section{M. A. Rozendaal}

Section of Plant Ecology and Biodiversity, Faculty of Science,

Utrecht University, P.O. Box 80084, 3508 TB Utrecht,

The Netherlands light were only congruent for a third of the traits evaluated. Four traits, amongst which leaf size, specific leaf area (SLA), and leaf area ratio at the metamer level (LAR) showed even opposite intra- and interspecific responses to light. Strikingly, these are classic traits that are thought to be of paramount importance for plant performance but that have completely different consequences within and across species. Sun trees of a given species had small leaves to reduce the heat load, but light-demanding species had large leaves compared to shade-tolerants, probably to outcompete their neighbors. Shade trees of a given species had a high SLA and LAR to capture more light in a light-limited environment, whereas shade-tolerant species have wellprotected leaves with a low SLA compared to lightdemanding species, probably to deter herbivores and enhance leaf lifespan. There was a leaf-size-mediated tradeoff between biomechanical and hydraulic safety, and the efficiency with which species can space their leaves and forage for light. Unexpectedly, metamer traits were more closely linked to leaf size than to regeneration light requirements, probably because leaf-size-related biomechanical and vascular constraints limit the trait combinations that are physically possible. This suggests that the leaf size spectrum overrules more subtle variation caused by the leaf economics spectrum, and that leaf size represents a more important strategy axis than previously thought.

Keywords Allocation · Foraging · Internode Leaf size $\cdot$ Light $\cdot$ Shade tolerance

\section{Introduction}

Two important characteristics that set plants aside from terrestrial animals are their sessile habit and indeterminate 
growth through the construction of modular units (Harper 1985). Being sessile, they can only explore the aboveground environment through the selective production and loss of metamers (Sterck et al. 2003). Metamers consist of an internode and the petiole and leaf at its distal end (Room et al. 2004). The internode and petiole are important for the spatial positioning and biomechanical and hydraulic support of the leaf, whereas the leaf is important for light interception and photosynthesis. Metamer traits therefore strongly determine the leaf display, carbon gain and competitive abilities of plants. Leaf display is defined here as the spacing of leaves, costs of spacing, and the amount of leaf area realized per unit biomass invested. Most comparative studies on plant organ design have focused on leaves only, because of their importance for the carbon, water and heat balance of the plant (e.g., Parkhurst and Loucks 1972; Reich et al. 1992; Wright et al. 2004). These leaf studies suggest that there is a leaf economics spectrum that varies from species with cheap, short-lived leaves with high carbon returns on biomass investment to species with expensive, long-lived leaves with slow returns on biomass investment (Wright et al. 2004). Yet, no new leaves can be produced without additional investment in internodes and petioles, and the notion of whether leaves are cheap or not can change dramatically once the investment into petioles and internodes is taken into account. Niinemets et al. (2007) found, for example, that species may invest up to $50 \%$ of their leaf and petiole biomass in petioles only, and that this biomass investment increased with the leaf size of the species. This figure does even not take the biomass investments in internodes into account, which can be considerable, especially so for tree species that make expensive woody tissues.

Leaf display and light capture depend on intra- and interspecific responses to light, and the size of the leaves (Falster and Westoby 2003; Pearcy et al. 2004, 2005). Nearly all our knowledge on intraspecific metamer responses to light comes from herbaceous (clonal) plants that vary internode length to forage for resources and explore resource-rich patches (Hutchings and de Kroon 1994). However, herbaceous plants and trees may forage for light in a fundamentally different way because they grow in a different environmental setting. Herbaceous plants grow in short vegetation with a predictable and steep vertical gradient in irradiance. For them it pays off to increase their internode length with shade, to overtop their neighbors and attain a better position in the vertical light profile of the canopy (Huber et al. 1998; Stuefer and Huber 1998). Forest trees grow in a tall vegetation, with a long, less predictable, and locally weak vertical gradient in irradiance. They decrease, rather than increase, their internode length with shade and invest the limited amount of carbon available in new leaves to enhance light interception (King 1991; Poorter 2001).
In most forests light is by far the most limiting resource for tree growth and survival, and species are thought to partition spatial and temporal gradients in irradiance (Pacala et al. 1996). Shade-tolerant and light-demanding species are adapted to different parts of these light gradients by showing interspecific variation in the way they forage for light and conserve acquired carbon. Light-demanding species regenerate in treefall gaps that close in due time because of a rapidly regrowing gap vegetation. Lightdemanding species might be expected to invest a large proportion of their metamer mass in internodes and petioles to enhance height growth and attain a better position in the vertical light profile of the regrowing stand. Shade-tolerant species regenerate in the shaded understory. They might be expected to invest a large proportion of their metamer mass in leaves to enhance light interception, and make tough well-protected leaves, petioles and internodes to enhance the leaf longevity and long-term carbon gain. Lightdemanding and shade-tolerant species differ indeed in their leaf longevity and specific leaf area (SLA; leaf area per unit leaf mass; Kikuzawa 1991; Reich et al. 1992; Poorter and Bongers 2006), but no hard data exist to test the hypotheses that they differ in the biomass investment and expansion costs of internodes and petioles.

Within plant communities, coexisting species show a large interspecific variation in leaf size (e.g., Ritchie and Olff 1999; Falster and Westoby 2003; Kleiman and Aarssen 2007), suggesting that leaf size might be an important axis of species variation in itself (Westoby et al. 2002). The size of the leaf has important consequences for the scale and precision with which plants forage for light; species with large leaves may intercept a large amount of light, whereas species with small leaves are better able to exploit finegrained environmental heterogeneity by positioning their leaves in light-rich micro-patches (Ritchie and Olff 1999). Many metamer traits may vary along with leaf size (e.g., White 1983; Ackerly and Donoghue 1998; Cornelissen 1999), a phenomenon that is also known as "Corner's rules". Corner (1949) suggested that the size of plant appendages (leaves, fruits) and axes (stem, branches) should be positively correlated because of vascular and biomechanical constraints. Large leaves require, for example, a disproportionate increase in biomass investment in support because the static load of the leaf scales with the cube of leaf length (Niklas 1999).

In this study we examine 11 metamer traits of sun and shade trees of 38 coexisting moist forest tree species that represent the majority of the trees in the community. Metamer traits are related to a quantitative and continuous measure of the regeneration light requirements of the species (i.e., the inverse of shade tolerance, Poorter et al. 2006a, 2006b). This is, to our knowledge, the first study to comprehensively analyze dimensions, biomass, and 
construction costs of internodes, petioles, and leaves and determine the relative strengths of intra- and interspecific variation. We address the following questions and corresponding hypotheses:

1. What are the intra- and interspecific metamer responses to light? We hypothesize that interspecific adaptations to light parallel intraspecific phenotypic adjustments to light as in both cases shade species and shade trees have to cope with a shortage of irradiance (Bazzaz 1979; Givnish 1988; Niinemets 2006).

2. What is the relative importance of the light requirements of regeneration and leaf size in determining the leaf display of the species? We hypothesize that, because of biomechanical constraints, leaf size overwhelms more subtle variation in leaf display related to the regeneration light requirements of the species.

\section{Materials and methods}

Study site

Research was carried out in the semi-evergreen tropical moist forest of La Chonta $\left(15^{\circ} 47^{\prime} \mathrm{S}, 62^{\circ} 55^{\prime} \mathrm{W}\right)$, Bolivia. The forest is situated on an extension of the Brazilian shield and receives an annual rainfall of $1,580 \mathrm{~mm}$ with a distinct dry period (potential evapotranspiration $>$ rainfall) of 1 month. About one-third of the canopy trees are deciduous in the dry season. The forest has an average canopy height of $27 \mathrm{~m}$, stem density of $368 \mathrm{ha}^{-1}$, basal area of $19.7 \mathrm{~m}^{2} \mathrm{ha}^{-1}$ and species richness of 59 species ha ${ }^{-1}$ [all data for trees $>10 \mathrm{~cm}$ diameter at breast height (DBH), Peña-Claros et al. 2008].

\section{Study species}

Thirty-eight of the most abundant tree species were selected, representing $77 \%$ of all stems larger than $10 \mathrm{~cm}$ DBH (Instituto Boliviano de Investigación Forestal, unpublished data). The species differed in shade tolerance and adult stature [Electronic supplementary material (ESM), Appendix]. Poorter et al. (2006a, 2006b) provided an independent, objective, and continuous measure of the regeneration light requirements of the species (i.e., the inverse of shade tolerance) by analyzing the crown exposure (CE) for each species in relation to the height of individual trees. This allows one to go beyond the subjective classification into pioneers and shade tolerants, and to show how species traits change gradually and continuously with the light requirements of the species. On average 662 individuals (range 41-9,319) per species were measured over their whole size range for their height and CE (Dawkins and
Field 1978). The CE varies from 1 , if a tree does not receive any direct light, to 2 if it receives lateral light, 3 if it receives overhead light on part of the crown (10-90\% of vertical projection of the crown exposed to vertical light), 4 when it receives full overhead light on the whole crown ( $>90 \%$ of vertical projection of the crown exposed to vertical light), and 5 when it has an emergent crown that has no obstructing foliage over an upward facing cone encompassing the crown, with angles of $45^{\circ}$ from horizontal. The CE can be measured repeatedly (average difference between two independent observers is $0.1 \pm 0.01 \mathrm{SE}$ ), and there is a good relation between $\mathrm{CE}$ and both canopy openness and incident radiation (Davies et al. 1998; Clark et al. 1993; Keeling and Phillips 2007). For each species the CE was related to tree height, using a multinomial regression analysis (Poorter et al. 2005, 2006a, 2006b). Using the regression equation, the average population-level $\mathrm{CE}$ at a standardized height of $2 \mathrm{~m}$ (juvenile CE) was calculated. Similar-sized individuals of the same species can be found under a wide range of CEs, but what counts from an evolutionary point of view is the average population-level CE of the species (Poorter et al. 2005).

\section{Metamer traits}

Five sun and five shade trees were selected per species (Rozendaal et al. 2006). Selected trees were not included in the study to describe the regeneration light requirements (Poorter et al. 2006a, 2006b), and were between 10-20 cm DBH and 8-15 m height. Erythrochiton fallax and Picramnia sellowii attain a maximum height of only 5-6 $\mathrm{m}$ and for these species the tallest individual trees were sampled. CE of the individual sampled trees was estimated by two independent observers. To this end the CE class 2 was divided into classes 1.5 (low amount of lateral light), 2 (medium lateral light), and 2.5 (high lateral light). Trees with a CE from 1 to 2.5 were classified as shade individuals, and trees with a CE of 3 and higher as sun individuals. Average CE of the shade trees was $1.80 \pm 0.03$ (mean $\pm \mathrm{SE}$ ) and of the sun trees was $3.40 \pm 0.04$.

Four metamers were collected per individual from the outer leaf layer midway between the bottom and top of the crown, providing in total 1,520 metamers. Young, fully expanded leaves without epiphylls and significant herbivore damage were selected, including the corresponding petioles and internodes (twig section below the leaf, between two nodes). Metamers were divided into leaves, petioles, and internodes. Nine species had compound leaves (ESM, Appendix), and for these whole leaves-rather than leaflets-were measured. Leaf size $\left(\right.$ in $\mathrm{cm}^{2}$ ) was determined by scanning the leaves with a flatbed scanner and analyzing the pictures with pixel-counting software (SigmaScan Pro 5; SPSS, Chicago). Throughout this article we 
use the term "leaf size" when referring to leaf area. Petiole length $(\mathrm{PL}$, in $\mathrm{cm})$ and internode length (IL, in $\mathrm{cm}$ ) were measured with a ruler or calliper. Metamer parts were ovendried for at least $48 \mathrm{~h}$ at $70^{\circ} \mathrm{C}$ and weighed for the metamer, leaf, petiole, and internode mass. From these data the SLA (the leaf blade area per unit leaf mass; in $\mathrm{cm}^{2} \mathrm{~g}^{-1}$ ), specific petiole length (SPL, the petiole length per unit petiole mass, in $\mathrm{cm}^{2} \mathrm{~g}^{-1}$ ), leaf area ratio (LAR, the leaf area per unit metamer mass, in $\mathrm{cm}^{2} \mathrm{~g}^{-1}$ ), specific internode length (SIL, the internode length per unit internode mass, in $\mathrm{cm}^{2} \mathrm{~g}^{-1}$ ), and metamer biomass fractions in leaf, petiole, and internode [leaf mass fraction (LMF), petiole mass fraction (PMF), internode mass fraction (IMF); dry mass per unit dry metamer mass; in \%] were calculated. Leaf size, internode length, and petiole length are important for the spatial positioning of the leaves. IMF and PMF indicate the biomass investment in biomechanical and hydraulic support, and the specific internode and petiole length reflect the efficiency of biomass investment for foraging. LMF, SLA, and LAR reflect the biomass investment at the metamer level in leaf display and light capture. Plants show strong ontogenetic changes in their whole-plant biomass fractions in leaves, stem, and branches, because of the different longevity of these components (Körner 1994). Especially for large trees it is therefore difficult to estimate how species partition their acquired carbon to different plant functions. By focusing on the growing branch tips only, we may get a first glimpse of how species invest their carbon aboveground (Falster and Westoby 2005). Of course, the annual new biomass allocation to stem thickening from base to current metamers may often exceed annual allocation to all metamers, but this is very difficult to measure.

\section{Data analysis}

For each tree the average leaf trait value was calculated, based on the average of the four leaves. Metamer responses to light were evaluated with a two-way ANOVA, with light and species as independent factors, and trees as unit of replication. All variables were $\log _{10}$ transformed prior to analysis to meet the assumption of ANOVA that the factors have an additive- and not a multiplicative effect on the dependent variable (Sokal and Rohlf 1995; Poorter and Garnier 1996). The variation explained by light, species, and the interaction was calculated as the sum of squares of the effect divided by the sum of squares of the model, and is analogous to $r^{2}$.

Associations among metamer traits were analyzed with a Pearson correlation, using the sun values of species as data points. Only sun values were used, as these indicate the full phenotypic expression of the species at "optimal" resource supply. The results are not likely to be different if shade values were used, as sun and shade values of leaf traits are strongly correlated across species (Rozendaal et al. 2006).
For this analysis an additional, 39th species was included (Zanthoxylum sprucei), because for this species only data on sun trees were collected.

Species-specific metamer traits were related to the juvenile CE and average leaf size of the species using Pearson correlation and regression analysis. A multiple regression was carried out with juvenile CE and $\log ($ leaf size) as independent variables, to evaluate whether both had independent significant effects on metamer traits. The standardized regression coefficient was used as an indicator of the relative importance of these variables in determining metamer traits. A normal type I regression was performed, as metamer traits were predicted from the independent variables. All statistical analyses were carried out using SPSS 12 (SPSS).

\section{Results}

Intraspecific responses to light

Species had a significant effect on all metamer traits, and explained on average $72 \%$ of the trait variation (range 4596\%; Table 1). Light had a significant effect on nine out of 11 metamer traits, although for these traits it explained little of the variation (average 4.3, range 0.1-17.2\%). There was a significant species $\times$ light interaction in four cases, which explained an additional $3.2 \%$ of the variation for these cases. Sun leaves had a significantly larger metamer mass but smaller leaf size, and statistically similar internode and petiole length compared to shade leaves. Shade leaves had a significantly larger biomass fraction of the metamers in leaves (LMF) and petioles (PMF), and a smaller biomass fraction in internodes (IMF) compared to sun leaves. Shade leaves had, compared to sun leaves, a more efficient leaf display per unit biomass invested; they had a significantly higher SLA, LAR, specific internode length, and SPL.

\section{Interspecific responses to light}

We used the juvenile $\mathrm{CE}$ as an independent, quantitative measure of the regeneration light requirements of the species. All metamer traits but three (internode length, IMF, SPL), were significantly correlated with the juvenile CE (Table 2). Petiole length (Fig. 1a) was positively correlated with the juvenile CE. The biomass fraction in petioles increased and the biomass fraction in leaves decreased with the juvenile CE (Fig. 2). Leaf size (Fig. 3) and metamer mass were also positively correlated with the juvenile CE. Finally the SLA and LAR were positively related to juvenile CE, although for LAR this was marginally significant ( $r=0.30$ and $P=0.061$ for log-transformed LAR values, $r=0.35$ and $P=0.029$ for untransformed LAR values). 
Table 1 ANOVA results of the dependence of metamer traits on species $(d f=37)$, light environment $(d f=1)$, and the interaction between species and light $(d f=37)$. The direction of intra- and interspecific responses to light is also indicated. $d f=291-304$ for the error term. Partial coefficients of determination $\left(r^{2}\right)$, significance levels $(P)$, and average $(A v g$. ) trait values for shade and sun trees are shown

\begin{tabular}{|c|c|c|c|c|c|c|c|c|c|c|c|}
\hline \multirow[t]{2}{*}{ Variable (unit) } & \multicolumn{2}{|c|}{ Species } & \multicolumn{2}{|l|}{ Light } & \multicolumn{2}{|c|}{ Spp. $\times$ Light } & \multirow{2}{*}{$\begin{array}{l}\text { Model } \\
r^{2}\end{array}$} & \multirow{2}{*}{$\begin{array}{l}\text { Shade } \\
\text { Avg. }\end{array}$} & \multirow{2}{*}{$\begin{array}{l}\text { Sun } \\
\text { Avg. }\end{array}$} & \multicolumn{2}{|c|}{ Light response } \\
\hline & $r^{2}$ & $P$ & $r^{2}$ & $P$ & $r^{2}$ & $P$ & & & & Intraspecific & Interspecific \\
\hline Leaf size $(\mathrm{LS})\left(\mathrm{cm}^{2}\right)$ & 0.939 & $* * *$ & 0.001 & * & 0.008 & ns & 0.95 & 116.5 & 109.1 & - & + \\
\hline Internode length $(\mathrm{IL})(\mathrm{cm})$ & 0.535 & $* * *$ & 0.003 & ns & 0.052 & ns & 0.59 & 1.45 & 1.57 & 0 & 0 \\
\hline Petiole length (PL) (cm) & 0.964 & $* * *$ & 0.000 & ns & 0.006 & $*$ & 0.97 & 2.64 & 2.60 & 0 & + \\
\hline Metamer mass (MM) $(\mathrm{g})$ & 0.912 & $* * *$ & 0.007 & $* * *$ & 0.012 & 0.06 & 0.93 & 0.730 & 0.901 & + & + \\
\hline Internode mass fraction $(\mathrm{IMF})^{\mathrm{a}}(\%)$ & 0.449 & $* * *$ & 0.009 & $*$ & 0.073 & ns & 0.53 & 6.3 & 7.3 & + & 0 \\
\hline Petiole mass fraction $(\mathrm{PMF})^{\mathrm{a}}(\%)$ & 0.937 & $* * *$ & 0.001 & $*$ & 0.012 & $* *$ & 0.95 & 4.6 & 4.4 & - & + \\
\hline Leaf mass fraction $(\mathrm{LMF})^{\mathrm{a}}(\%)$ & 0.474 & $* * *$ & 0.006 & $*$ & 0.088 & $*$ & 0.57 & 86.0 & 84.9 & - & - \\
\hline Specific leaf area (SLA) $\left(\mathrm{cm}^{2} \mathrm{~g}^{-1}\right)$ & 0.488 & $* * *$ & 0.164 & $* * *$ & 0.030 & ns & 0.68 & 194.6 & 150.0 & - & + \\
\hline Leaf area ratio $(\mathrm{LAR})\left(\mathrm{cm}^{2} \mathrm{~g}^{-1}\right)$ & 0.449 & $* * *$ & 0.172 & $* * *$ & 0.046 & ns & 0.67 & 167.4 & 127.3 & - & $t^{\mathrm{b}}$ \\
\hline $\begin{array}{l}\text { Specific petiole length (SPL) } \\
\left(\mathrm{cm} \mathrm{g}^{-1}\right)\end{array}$ & 0.871 & $* * *$ & 0.010 & $* * *$ & 0.015 & $\mathrm{~ns}$ & 0.90 & 81.4 & 69.4 & - & 0 \\
\hline $\begin{array}{l}\text { Specific internode length (SIL) } \\
\left(\mathrm{cm} \mathrm{g}^{-1}\right)\end{array}$ & 0.862 & $* * *$ & 0.015 & $* * *$ & 0.020 & $* *$ & 0.90 & 33.2 & 25.0 & - & - \\
\hline
\end{tabular}

For intraspecific light responses the data are from this table, for interspecific light responses the data are from the correlation between metamer traits and CE (Table 2). Sun leaves/light-demanding species have significantly smaller values ( - ) compared to shade leaves/shade-tolerant species; sun leaves/light-demanding species have significantly larger values $(+)$ compared to shade leaves/shade-tolerant species; or there is no significant effect $(0)$

$* P<0.05, * * P<0.01, * * * P<0.001, \mathrm{~ns} P>0.05$

a Note that the IMF, PMF, and LMF do not add up to $100 \%$ because they are based on back-transformed logarithmic mean values

b Marginally significant for log-transformed values, significant for untransformed values

Table 2 Pearson correlations between juvenile crown exposure $(C E)$, LS, and ten metamer traits of sun trees of 39 moist forest tree species. Correlations in bold are significant at $P<0.05$. For trait abbreviations see Table 1

\begin{tabular}{|c|c|c|c|c|c|c|c|c|c|c|c|}
\hline & $\mathrm{CE}$ & LS & IL & PL & MM & IMF & PMF & LMF & SLA & LAR & SPL \\
\hline LS & 0.43 & & & & & & & & & & \\
\hline $\mathrm{IL}$ & 0.18 & 0.20 & & & & & & & & & \\
\hline PL & 0.49 & 0.85 & -0.08 & & & & & & & & \\
\hline MM & 0.33 & 0.97 & 0.24 & 0.79 & & & & & & & \\
\hline IMF & -0.03 & -0.30 & 0.74 & -0.39 & -0.28 & & & & & & \\
\hline PMF & 0.40 & 0.72 & -0.29 & 0.94 & 0.65 & -0.51 & & & & & \\
\hline LMF & -0.47 & -0.34 & -0.40 & -0.45 & -0.32 & -0.41 & -0.37 & & & & \\
\hline SLA & 0.40 & -0.11 & 0.01 & 0.06 & -0.30 & 0.14 & 0.03 & -0.20 & & & \\
\hline LAR & $0.30^{\mathrm{a}}$ & -0.19 & -0.08 & -0.05 & -0.38 & 0.05 & -0.05 & 0.02 & 0.98 & & \\
\hline SPL & -0.14 & -0.86 & -0.23 & -0.55 & -0.93 & 0.28 & -0.46 & 0.17 & 0.49 & 0.54 & \\
\hline SIL & -0.35 & -0.93 & 0.02 & -0.86 & -0.94 & 0.38 & -0.77 & 0.39 & 0.28 & 0.38 & 0.86 \\
\hline
\end{tabular}

All traits but CE were log-transformed for the analysis

${ }^{a}$ Marginally significant for log-transformed values, significant for untransformed values

\section{Metamer traits and leaf size}

Metamer dimensions of sun trees varied dramatically among species. For example, the leaf size varied 460 -fold $\left(6-2,958 \mathrm{~cm}^{2}\right)$, the petiole length 200 -fold $(0.2-41 \mathrm{~cm})$, and internode length 60 -fold $(0.17-4.36 \mathrm{~cm})$ (ESM, Appendix). The LMF varied only 1.2-fold (75-92\%), the IMF 27-fold
(1-22\%), and the PMF ranged from 0 to $21 \%$. A large part of this interspecific variation in metamer traits was associated with variation in leaf size (Table 2). Large-leafed species had longer petioles (Fig. 1b) and larger metamer masses. PMF was positively correlated with leaf size and LMF negatively, whereas IMF did not vary significantly with leaf size (Fig. 2). The specific petiole and internode 
Fig. 1 Petiole length, specific petiole length (SPL) and specific internode length $(S I L)$ of 39 moist forest tree species in relation to juvenile crown exposure $(\mathbf{a}, \mathbf{c}, \mathbf{e})$ and leaf size $(\mathbf{b}, \mathbf{d}, \mathbf{f})$. Regression lines, significance levels, and coefficients of determination $\left(r^{2}\right)$ are shown. Species abbreviations comprise first three letters of the genus name followed by the first letter of the specific name (see ESM, Appendix). $* P<0.05, * * P<0.01$, $* * * P<0.001$
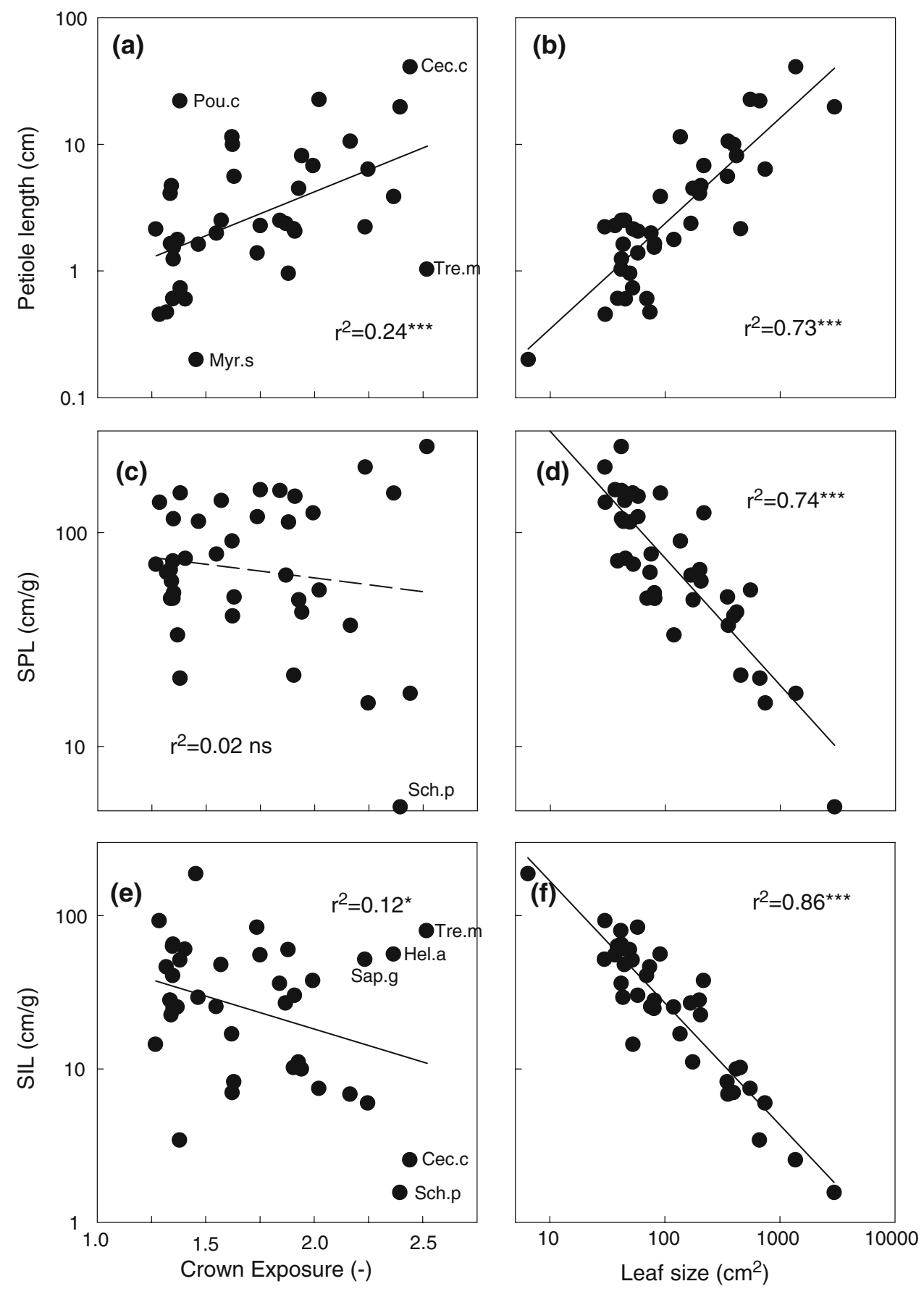

lengths decreased significantly with leaf size (Fig. 1d, f) and SLA and LAR did not correlate significantly with leaf size.

Relative importance of regeneration light requirements and leaf size

A multiple regression analysis was performed to evaluate whether leaf size and juvenile CE had independent effects on metamer traits (Table 3). Leaf size had a highly significant effect on all metamer traits but two. For leaf size the results of the multiple regression analysis and correlation analysis were largely the same, with the exception of SLA, LAR, and IMF, which became significantly and negatively related to leaf size once the differences in species light requirements were taken into account. Standardized regression coefficients were in general stronger for leaf size than those for juvenile $\mathrm{CE}$, suggesting that leaf size is the most important determinant of leaf display. For juvenile CE the results of the multiple regression analysis and correlation analysis were quite different. Juvenile CE had a significant independent effect on only five metamer traits (Table 3). 
Fig. 2 Leaf mass fraction $(L M F)$, petiole mass fraction $(P M F)$, and internode mass fraction $(I M F)$ of 39 moist forest tree species in relation to juvenile crown exposure $(\mathbf{a}, \mathbf{c}, \mathbf{e})$ and leaf size $(\mathbf{b}, \mathbf{d}, \mathbf{f})$. Regression lines, significance levels, and coefficients of determination $\left(r^{2}\right)$ are shown. Species abbreviations comprise the first three letters of the genus name followed by the first letter of the specific name (see ESM, Appendix). $* P<0.05, * * P<0.01$, $* * * P<0.001$
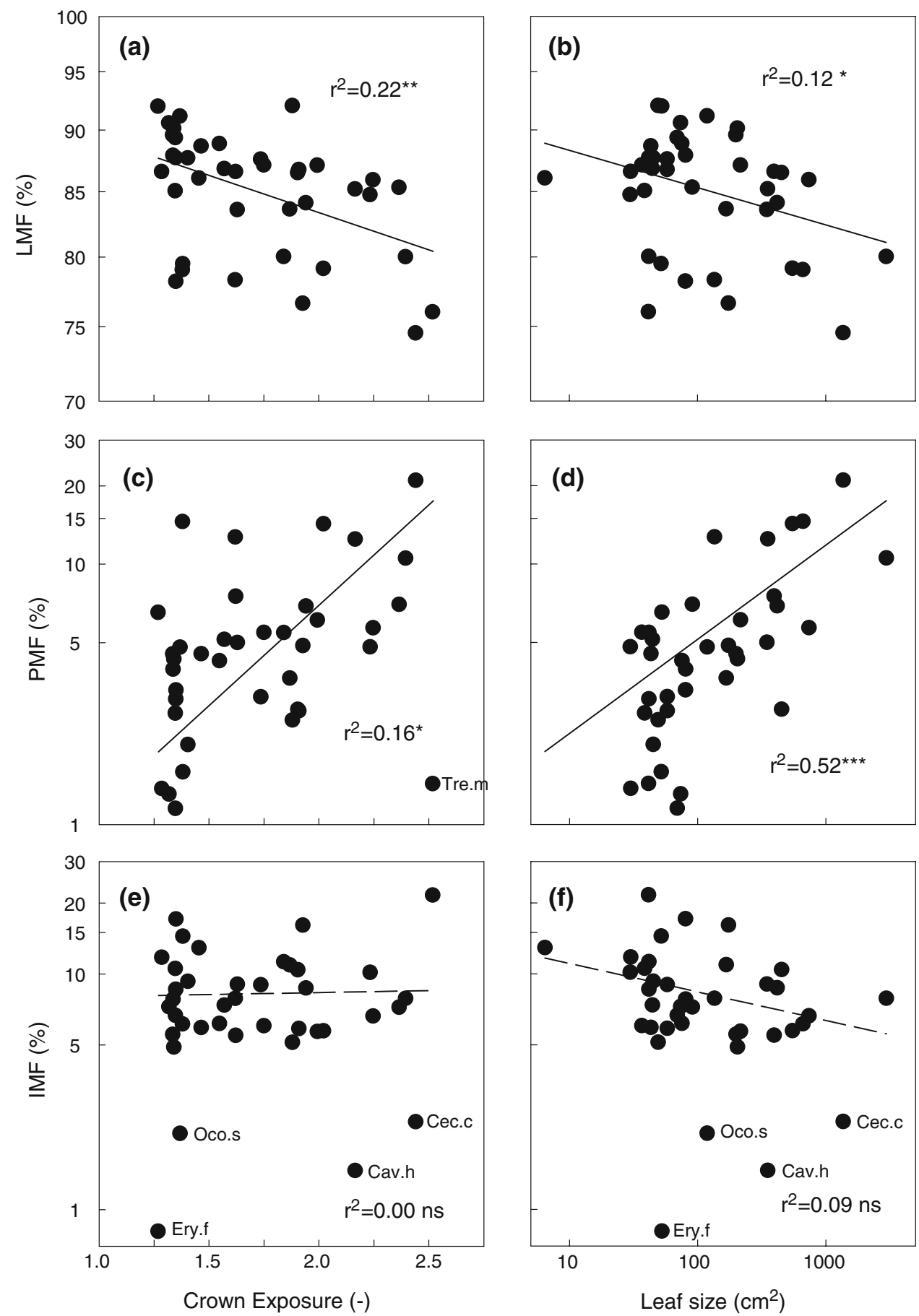

CE had now a significant positive effect on SPL and LAR, and a significant, negative effect on metamer mass. LMF and SLA were still significantly associated with CE in the multiple regression analysis.

\section{Discussion}

We analyzed how tropical tree species show intraspecific responses and interspecific adaptations in their leaf display to light. Most of the variation in metamer traits was explained by species, whereas light had only a minor effect on the phenotypic expression of metamer traits. Across species metamer traits were strongly associated with leaf size, and to a lesser extent with the light requirements for regeneration.

Intraspecific responses to light

Intraspecific light responses at the metamer level (Table 1) paralleled the well-established responses for small seedlings 
Table 3 Multiple regression of metamer traits of sun trees on the independent variables juvenile CE and LS. Standardized regression coefficients $(\beta)$, significance levels $(P)$, and coefficients of determination of the model $\left(r^{2}\right)$ are shown. All variables but CE were log-transformed prior to analysis. For abbreviations see Table 1

\begin{tabular}{|c|c|c|c|c|c|}
\hline \multirow[t]{2}{*}{ Variable } & \multicolumn{2}{|l|}{$\mathrm{CE}$} & \multicolumn{2}{|c|}{ Leaf size } & \multirow[t]{2}{*}{$r^{2}$} \\
\hline & $\beta$ & $P$ & $\beta$ & $P$ & \\
\hline $\mathrm{IL}$ & 0.11 & n.s. & 0.16 & n.s. & 0.05 \\
\hline PL & 0.16 & n.s. & 0.78 & $* * *$ & 0.75 \\
\hline MM & -0.10 & $*$ & 1.02 & $* * *$ & 0.96 \\
\hline IMF & 0.19 & n.s. & -0.38 & $*$ & 0.12 \\
\hline PMF & 0.11 & n.s. & 0.67 & $* * *$ & 0.53 \\
\hline LMF & -0.39 & $*$ & -0.18 & n.s. & 0.24 \\
\hline SLA & 0.55 & $* * *$ & -0.35 & $*$ & 0.26 \\
\hline LAR & 0.47 & $* *$ & -0.40 & $*$ & 0.22 \\
\hline SPL & 0.27 & $* *$ & -0.97 & $* * *$ & 0.80 \\
\hline SIL & 0.06 & n.s. & -0.95 & $* * *$ & 0.86 \\
\hline
\end{tabular}

$* P<0.05, * * P<0.01, * * * P<0.001$, ns $P>0.05$

at the whole-plant level (reviewed in Walters and Reich 1999; Poorter 2005), and for large trees at the leaf level (Bongers and Popma 1988; Markesteijn et al. 2007). Sun leaves were smaller than shade leaves, probably to reduce the boundary layer thickness, increase convective heat loss, and prevent overheating of the leaf (Parkhurst and Loucks 1972). At the same time they were thicker (Rozendaal et al. 2006) and heavier with a lower SLA (Table 1), thus enhancing photosynthetic carbon gain per unit leaf area (Rijkers et al. 2000). Shade trees had, compared to sun trees, a larger biomass fraction of the metamers in leaves but a smaller biomass fraction in internodes. By allocating more biomass in leaf area than in support tissue they enhance light interception in a light-limited environment (Table 1; cf. King 1991; Poorter 2001). The specific internode and petiole length increased in the shade (cf. Huber et al. 1998; Stuefer and Huber 1998), indicating that shade plants space their leaves at lower cost to reduce self-shading and forage for light. SLA and LAR increased as well in the shade, suggesting that shade plants invest their biomass more efficiently to display their leaves. Interestingly, the petiole length and biomass fraction in petioles did not vary or varied little in response to light environment (Table 1; Niinemets and Kull 1999; Niinemets and Fleck 2002), which suggests that petiole traits are phylogenetically fixed and do not allow plants to forage plastically for light. Instead, petiole twisting, and changes in petiole and leaf angles might be an energetically cheaper and more efficient plastic response to reduce self-shading and enhance light interception of the plant (Valladares 1999; Galvez and Pearcy 2003).

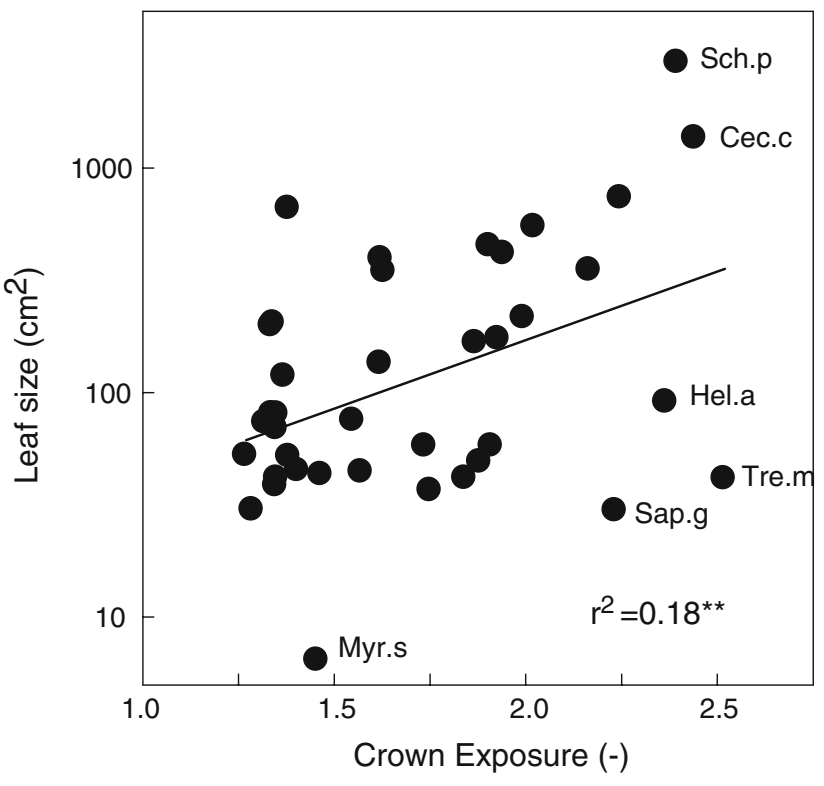

Fig. 3 Relationship between leaf area and juvenile crown exposure of 39 moist forest tree species. Regression lines, significance levels, and coefficients of determination $\left(r^{2}\right)$ are shown. Species abbreviations comprise the first three letters of the genus name followed by the first letter of the specific name (see ESM, Appendix). ${ }^{* *} P<0.01$

\section{Interspecific responses to light}

Light-demanding species had, on average, larger leaves (Fig. 3) and petioles (Fig. 1a) than more shade-tolerant species (Table 2; cf. Popma et al. 1992). However, the relationship showed substantial scatter and some typical pioneers such as Sapium, Trema, and Heliocarpus possessed small rather than large leaves (Fig. 3). This suggests that pioneers may employ two different strategies to forage for light in a dynamic environment: they either produce small leaves on "throw-away branches" that can easily be shed and replaced once overshaded (Ackerly 1996), or they produce large leaves and petioles to forage plastically for light and overtop and outshade their neighbors in a rapidly regrowing gap vegetation (Horn 1971). The large petioles function as cheap throw-away branches (Givnish 1984) thus permitting the species to postpone branching and to invest their biomass in vertical height growth instead (King 1998; Poorter et al. 2006a, 2006b; Sterck et al. 2006). In contrast, light-demanding species from arid vegetation tend to have small, rather than large, leaves (Bragg and Westoby 2002). Water availability, rather than light availability, limits plant growth in these dry environments, especially so in exposed early successional habitats. Here the light-demanding species have small leaves to increase convective heat loss, reduce transpiration, and to prevent the leaf from attaining supra-optimal temperatures for photosynthesis (Knight and Ackerly 2003). Leaf size may therefore play different ecological roles in dry and wet climates. 
Many correlations between metamer traits and juvenile $\mathrm{CE}$ were found because light-demanding species had larger leaves and because many traits change with leaf size (Table 2). The multiple regression analyses indicated that, independent of leaf size, juvenile CE had only a significant effect on SPL, leaf mass fraction, SLA, LAR, and metamer mass (Table 3). A high SPL allows light-demanding species to forage more cheaply for light. Interestingly, lightdemanding species invested a smaller proportion of their metamer mass in leaves compared to shade-tolerant species (Fig. 2a), which is in contrast to what is found for seedlings (Walters and Reich 1999; Poorter 2005). Light-demanding species compensate for their lower LMF by having a disproportionately higher SLA (Table 3), resulting in a positive relation between the leaf area per unit metamer mass (LAR) and juvenile CE. New metamers are analogous to young seedlings, in the sense that no leaf shedding has occurred. A similar positive association between LAR and light requirements has also been found at the whole-plant level for seedlings of rain forest tree species (Kitajima 1994; Poorter 2005). A high LAR enables light-demanding species to realize fast growth rates, outcompete their neighbors, and rapidly complete their life cycle. The LAR advantage at the whole-plant level may, nonetheless, disappear over time once light-demanding species start to shed their short-lived leaves (Lusk 2004; Poorter and Rose 2005).

\section{Congruency of intra- and interspecific responses?}

It is often assumed that interspecific adaptations to light should parallel intraspecific phenotypic adjustments to light as in both cases shade species and shade trees have to cope with a shortage of irradiance (Bazzaz 1979; Givnish 1988; Niinemets 2006). However, this assumption is only valid in a third of the cases, as only four out of 11 traits showed similar intra- and interspecific responses to light (Table 1). Three traits showed different responses to light, in which the interspecific response was significant and the interspecific response was not, or vice versa. Four traits (leaf size, SLA, LAR, and PMF) even showed opposite intra- and interspecific responses to light (Table 1). Strikingly, three of these are "classic" traits that are thought to be of paramount importance for the performance of plants (Bazzaz 1979; Givnish 1988; Westoby et al. 2002) but that have completely different consequences within and across species. Sun trees have small leaves to reduce the heat load, but light-demanding species have large leaves, probably to outcompete their neighbors. Shade trees have a high SLA and LAR to capture more light in a light-limited environment, whereas shade-tolerant species have well-protected leaves with a low SLA (and hence, LAR) to deter herbivores (Coley 1983), enhance leaf lifespan, and to be able to pay back leaf investments in a low-light environment where carbon gain is low as well (Poorter and Bongers 2006; Poorter et al. 2006a, 2006b).

Metamer traits and leaf size

Average community-level leaf size varies in a predictable way along large-scale environmental gradients, with smaller leaves in drier, hotter, and nutrient-poor habitats (e.g., Schimper 1898; Werger and Ellenbroek 1978; Fonseca et al. 2000). However, within communities coexisting species show large interspecific variation in leaf size (cf. Fig. 3), suggesting that leaf size might be an important strategy axis of variation (Westoby et al. 2002). The importance of leaf size is underscored by the present study, which shows that leaf display traits are tightly linked to leaf size (Table 2), and that they are more determined by leaf size than by species' light requirements for regeneration (Table 3). Important features of the leaf economics spectrum (such as leaf lifespan, SLA, and mass-based assimilation) are closely linked with the species' light requirements for regeneration (Poorter and Bongers 2006; Lusk and Warton 2007). In combination this suggests that the leaf size spectrum overrules more subtle variation caused by the leaf economics' spectrum (cf. Niinemets et al. 2007), probably because leaf-size-related biomechanical and vascular constraints limit the trait combinations that are physically possible (see below).

The length of petioles increased with leaf size (Fig. 1b; cf. White 1983a, 1983b; Niinemets et al. 2006, 2007), whereas the length of the internodes did not. A likely reason for this difference is that small-leaved species tend to display their leaves in planes on either side of nearly horizontal twigs, while larger-leaved species tend to bear their leaves in spiral or dessucate three-dimensional displays on steeply angled twigs (King and Maindonald 1999). Hence, many small-leaved species reduce self-shading by having relatively long internodes, and many large-leaved species by having large petioles. Corner (1949) hypothesized that the size of plant axes and their appendages should be positively correlated because of biomechanical and/or vascular constraints; large leaves require more biomechanical and hydraulic support, which can be rendered by producing petioles and internodes with a wider cross-sectional area, leading to a lower SPL (Fig. 1d) and specific internode length (Fig. 1f). Metamer traits show therefore tight relationships with leaf size (Fig. 1d, f); the trait space far above the regression line is not filled because of biomechanical and hydraulic constraints, and the trait space far below the line is not filled because biotic selection pressure forces plants to use their biomass as efficiently as possible to space their leaves. The net result is a trade-off between biomechanical and hydraulic safety, and the efficiency with which species can space their leaves and forage for light. 
Large-leafed species invested a larger proportion of their metamer mass in petioles (Fig. 2d). Similarly, Niinemets et al. $(2006,2007)$ found that large-leaved species invested a larger proportion of their leaf and petiole mass in petioles. Large leaves require a disproportionate increase in biomass investment in support as the static loading of the leaf scales with the cube of petiole- and leaf length, and the dynamic loading due to wind drag scales isometrically with leaf area (Niklas 1999). The high biomass investment in petioles may also reflect a foraging strategy in which large leaves are spaced further apart to reduce self-shading and forage opportunistically for light. Petioles are more efficient spacer organs than internodes because they are cheaper to construct; species realized, on average, a petiole length of $86 \mathrm{~cm} \mathrm{~g}^{-1}$ biomass invested, compared to only $38 \mathrm{~cm}$ for internodes (ESM, Appendix). Petioles function as cheap spacer organs to explore environmental heterogeneity in the short term, whereas internodes function as expensive spacer organs to construct persistent branches or stems to explore the environment in the long term (Sterck and Schieving 2007). Falster and Westoby (2003) found for 38 species from Australian dry forest and woodlands that most of the interspecific variation in carbon gain was caused by self-shading. Self-shading decreased rather than increased with leaf size, because large-leaved species tend to have longer internodes and petioles (cf. Table 2) and thus can space their leaves further apart (Niklas 1988; Takenaka 1994).

Recently, there has been a strong interest in the scaling relationships between plant physiological activity and morphology on the one hand, and the size of plants and their tissues on the other hand (Niinemets et al. 2007; Niklas et al. 2007). The scaling relationship between leaf size and SLA is of special interest, because SLA drives most of the light interception of plants. In a global cross-species analysis, Niklas et al. (2007) found a negative relationship between SLA and leaf size, suggesting that species with larger leaves have diminishing returns on the biomass they invest in light capture, and that there should be run-away selection for species with smaller leaves. The analysis of Niklas et al. (2007) was based on species from widely different biomes and habitats. In contrast, in our study we did not find a significant relation between SLA and leaf size across coexisting tree species within a single plant community $(r=-0.11, P=0.50)$. Such a negative relationship became only apparent once the regeneration light requirement of the species had been taken into account (Table 3; standardized regression coefficient between SLA and leaf size is $-0.35, P<0.05)$. This means that the results of global meta-analyses can not be directly translated to local scales and that the species' ecology should be put back into the equation of global analyses to obtain more meaningful results (cf. Lusk and Warton 2007).
In sum, metamer traits vary tremendously across species, and show modest changes in response to light, and intraand interspecific responses to light are only partly congruent with each other. Metamer traits were more closely linked to leaf size than to regeneration light requirements because of biomechanical constraints and vascular needs. Leaf size partly overrules more subtle life history variation in shade tolerance and represents an important axis of cross-species variation.

Acknowledgements We thank Victor-Hugo Hurtado for his indispensable help with the fieldwork, and staff and personnel of the Instituto Boliviano de Investigación Forestal for logistic support. Frank Sterck, Frans Bongers and four anonymous reviewers provided very useful comments that substantially improved the manuscript. L. Poorter was supported by Veni grant 863.02.007 from the Netherlands Organisation of Scientific Research, and a fellowship from the Wageningen Graduate School Production Ecology and Resource Conservation. D. M. A. Rozendaal was supported by the Alberta Mennega Stichting, Miquel Fonds and Stichting Fonds Dr Christine Buisman.

Open Access This article is distributed under the terms of the Creative Commons Attribution Noncommercial License which permits any noncommercial use, distribution, and reproduction in any medium, provided the original author(s) and source are credited.

\section{References}

Ackerly DD (1996) Canopy structure and dynamics: integration of growth processes in tropical pioneer trees. In: Mulkey SS, Chazdon RL, Smith AP (eds) Tropical forest plant physiology. Chapman \& Hall, London, pp 619-658

Ackerly DD, Donoghue MJ (1998) Leaf size, sapling allometry, and Corner's rules: phylogeny and correlated evolution in maples (Acer). Am Nat 152:767-791

Bazzaz FA (1979) Physiological ecology of plant succession. Annu Rev Ecol Syst 10:351-371

Bongers F, Popma J (1988) Is exposure-related variation in leaf characteristics of tropical rain forest species adaptive? In: Werger MJA, van der Aart PJM, During HJ, Verhoeven JTA (eds) Plant form and vegetation structure. SPB, The Hague, pp 191-200

Bragg JG, Westoby M (2002) Leaf size and foraging for light in a sclerophyll woodland. Funct Ecol 16:633-639

Clark DB, Clark DA, Rich PM (1993) Comparative analysis of microhabitat utilization by saplings of nine tree species in neotropical rain forest. Biotropica 25:397-407

Coley PD (1983) Herbivory and defence characteristics of tree species in a lowland tropical forest. Ecol Monogr 53:209-233

Cornelissen JHC (1999) A triangular relationship between leaf size and seed size among woody species: allometry, ontogeny, ecology and taxonomy. Oecologia 118:248-255

Corner EJH (1949) The Durian theory or the origin of the modern tree. Ann Bot 13:367-414

Davies SJ, Palmiotto PA, Ashton PS, Lee HS, Lafrankie JV (1998) Comparative ecology of 11 sympatric species of Macaranga in Borneo: tree distribution in relation to horizontal and vertical resource heterogeneity. J Ecol 86:662-673

Dawkins HC, Field DRB (1978) A long-term surveillance system for British woodland vegetation. Department of Forestry, Oxford University, Oxford 
Falster DS, Westoby M (2003) Leaf size and angle vary widely across species: what consequences for light interception? New Phytol 158:509-525

Falster DS, Westoby M (2005) Alternative height strategies among 45 dicot rain forest species from tropical Queensland, Australia. J Ecol 93:521-535

Fonseca CR, Overton JM, Collins B (2000) Shifts in trait-combinations along rainfall and phosphorus gradients. J Ecol 88:964-977

Galvez D, Pearcy RW (2003) Petiole twisting in the crowns of Psychotria limonensis: implications for light interception and daily carbon gain. Oecologia 135:22-29

Givnish TJ (1984) Leaf and canopy adaptations in tropical forests. In: Medina E, Mooney HA, Vasquez-Yanes C (eds) Physiological ecology of plants in the wet tropics. Junk, The Hague, pp 51-84

Givnish TJ (1988) Adaptation to sun and shade-a whole-plant perspective. Aust J Plant Physiol 15:63-92

Harper JL (1985) Modules, branches, and the capture of resources. In: Jackson JBC, Buss LW, Cook RE (eds) Population biology and evolution of clonal organisms. Yale University press, New Haven, pp 1-33

Horn HS (1971) The adaptive geometry of trees. Princeton University Press, Princeton

Huber H, Fijan A, During HJ (1998) A comparative study of spacer plasticity in erect and stoloniferous herbs. Oikos 81:576-586

Hutchings MJ, de Kroon H (1994) Foraging in plants: the role of morphological plasticity in resource acquisition. Adv Ecol Res 25:160-238

Keeling HC, Phillips OL (2007) A calibration method for the crown illumination index for assessing forest light environments. For Ecol Manage 242:431-437

Kikuzawa K (1991) A cost-benefit-analysis of leaf habit and leaf longevity of trees and their geographical pattern. Am Nat 138:12501263

King DA (1991) Correlations between biomass allocation, relative growth rate and light environment in tropical forest saplings. Funct Ecol 5:485-492

King DA (1998) Influence of leaf size on tree architecture: first branch height and crown dimensions in tropical rain forest trees. Trees 12:438-445

King DA, Maindonald JH (1999) Tree architecture in relation to leaf dimensions and tree stature in temperate and tropical rain forests. J Ecol 87:1012-1024

Kitajima K (1994) Relative importance of photosynthetic traits and allocation patterns as correlates of seedling shade tolerance of 13 tropical trees. Oecologia 98:419-428

Kleiman D, Aarssen LW (2007) The leaf size/number trade-off in trees. J Ecol 95:376-382

Knight CA, Ackerly DD (2003) Evolution and plasticity of photosynthetic thermal tolerance, specific leaf area and leaf size: congeneric species from desert and coastal environments. New Phytol 160:337-347

Körner CH (1994) Biomass fractionation in plants: a reconsideration of definitions based on plant functions. In: Roy J, Garnier E (eds) A whole plant perspective on carbon-nitrogen interactions. SPB, The Hague, pp 173-185

Lusk CH (2004) Leaf area and growth of juvenile temperate evergreens in low light: species of contrasting shade tolerance change rank during ontogeny. Funct Ecol 18:820-828

Lusk CH, Warton DI (2007) Global meta-analysis shows that relationships between leaf mass per area and species shade tolerance depend on leaf habit and ontogeny. New Phytol 176:764-774

Markesteijn L, Poorter L, Bongers F (2007) Light-dependent leaf trait variation in 43 tropical dry forest tree species. Am J Bot 94:515-525

Niinemets U (2006) The controversy over traits conferring shade-tolerance in trees: ontogenetic changes revisited. J Ecol 94:464-470
Niinemets U, Fleck S (2002) Leaf biomechanics and biomass investment in support in relation to long-term irradiance in Fagus. Plant Biol 4:523-534

Niinemets U, Kull O (1999) Biomass investment in leaf lamina versus lamina support in relation to growth irradiance and leaf size in temperate deciduous trees. Tree Physiol 19:349-358

Niinemets U, Portsmuth A, Tobias M (2006) Leaf size modifies support biomass distribution among stems, petioles and mid-ribs in temperate plants. New Phytol 171:91-104

Niinemets U, Portsmuth A, Tena D, Tobias M, Matesanz S, Valladares F (2007) Do we underestimate the importance of leaf size in plant economics? Disproportional scaling of support costs within the spectrum of leaf physiognomy. Ann Bot 100:283-303

Niklas KJ (1988) The role of phyllotactic pattern as a "developmental constraint" on the interception of light by leaf surfaces. Evolution 42:1-16

Niklas KJ (1999) A mechanical perspective on foliage leaf form and function. New Phytol 143:19-31

Niklas KJ, Cobb ED, Niinemets U, Reich PB, Sellin A, Shipley B, Wright IJ (2007) "Diminishing returns" in the scaling of functional leaf traits across and within species groups. Proc Natl Acad Sci USA 104:8891-8896

Pacala SW, Canham CD, Saponara J, Silander J, Kobe RK, Ribbens E (1996) Forest models defined by field measurements: estimation, error analysis and dynamics. Ecol Monogr 66:1-43

Parkhurst DF, Loucks OL (1972) Optimal leaf size in relation to environment. J Ecol 60:505-537

Pearcy RW, Valladares F, Wright SJ, de Paulis EL (2004) A functional analysis of the crown architecture of tropical forest Psychotria species: do species vary in light capture efficiency and consequently in carbon gain and growth? Oecologia 139:163-177

Pearcy RW, Muraoka H, Valladares F (2005) Crown architecture in sun and shade environments: assessing function and trade-offs with a three-dimensional simulation model. New Phytol 166:791800

Peña-Claros M, Fredericksen TS, Alarcón A, Blate GM, Choque U, Leaño C, Licona JC, Mostacedo B, Pariona W, Villegas Z, Putz FE (2008) Beyond reduced impact logging: silvicultural treatments to increase growth rates of tropical trees. For Ecol Manage. doi:10.1016/j.foreco.2007.12013

Poorter L (2001) Light-dependent changes in allocation and their effects on the growth of rain forest tree species. Funct Ecol 15:113-123

Poorter L (2005) Resource capture and use by tropical forest tree seedlings and their consequences for competition. In: Burslem DFRP, Pinard MA, Hartley SE (eds) Biotic interactions in the tropics: their role in the maintenance of species diversity. Cambridge University Press, Cambridge, pp 35-64

Poorter L, Bongers F (2006) Leaf traits are good predictors of plant performance across 53 rain forest species. Ecology 87:1733-1743

Poorter H, Garnier E (1996) Plant growth analysis: an evaluation of experimental design and computational methods. J Exp Bot 47:1342-1353

Poorter L, Rose SA (2005) Light-dependent changes in the relationship between seed mass and seedling traits: a meta-analysis for rain forest tree species. Oecologia 142:378-387

Poorter L, Bongers F, Sterck FJ, Wöll H (2005) Beyond the regeneration phase: differentiation of height-light trajectories among tropical tree species. J Ecol 93:256-267

Poorter L, Bongers L, Bongers F (2006a) Architecture of 54 moist-forest tree species: traits, trade-offs, and functional groups. Ecology 87:1289-1301

Poorter H, Pepin S, Rijkers T, de Jong Y, Evans JR, Korner C (2006b) Construction costs, chemical composition and payback time of high- and low-irradiance leaves. J Exp Bot 57:355-371 
Popma J, Bongers F, Werger MJA (1992) Gap-dependence and leaf characteristics of trees in a tropical lowland rain forest in Mexico. Oikos 63:207-214

Reich PB, Walters MB, Ellsworth DS (1992) Leaf life-span in relation to leaf, plant, and stand characteristics among diverse ecosystems. Ecol Monogr 62:365-392

Rijkers T, Pons TL, Bongers F (2000) The effect of tree height and light availability on photosynthetic leaf traits of four neotropical species differing in shade tolerance. Funct Ecol 14:77-86

Ritchie ME, Olff H (1999) Spatial scaling laws yield a synthetic theory of biodiversity. Nature 400:557-560

Room PM, Mailette L, Hanan JS (2004) Module and metamer dynamics and virtual plants. Adv Ecol Res 25:105-157

Rozendaal DMA, Hurtado VH, Poorter L (2006) Plasticity in leaf traits of 38 tropical tree species in response to light; relationships with light demand and adult stature. Funct Ecol 20:207-216

Schimper AFW (1898) Pflanzengeographie auf Physiologischer Grundlage. Fischer, Jena

Sokal RR, Rohlf FJ (1995) Biometry. Freeman \& Company, New York

Sterck FJ, Schieving F (2007) Selection determines ontogenetic patterns in 3D growth of trees: effects of scaling, light, carbon economy, and meristem activity. Ecol Monogr 77:405-420

Sterck FJ, Bongers F, During HJ, Martinez-Ramos M, de Kroon H (2003) Module responses in a tropical forest tree analyzed with a matrix model. Ecology 84:2751-2761

Sterck FJ, van Gelder HA, Poorter L (2006) Mechanical branch constraints contribute to life-history variation across tree species in a Bolivian forest. J Ecol 94:1192-1200
Stuefer JF, Huber H (1998) Differential effects of light quantity and spectral light quality on growth, morphology and development of two stoloniferous Potentilla species. Oecologia 117:1-8

Takenaka A (1994) Effects of leaf blade narrowness and petiole length on the light capture efficiency of a shoot. Ecol Res 9:109-114

Valladares F (1999) Architecture, ecology, and the evolution of plant crowns. In: Pugnaire F, Valladares F (eds) The handbook of functional plant ecology. Dekker, New York, pp 122-177

Walters MB, Reich PB (1999) Low-light carbon balance and shade tolerance in the seedlings of woody plants: do winter deciduous and broad-leaved evergreen species differ? New Phytol 143:143-154

Werger MJA, Ellenbroek GA (1978) Leaf size and leaf consistence of a riverine forest formation along a climatic gradient. Oecologia 34:297-308

Westoby M, Falster DS, Moles A, Vesk P, Wright IJ (2002) Plant ecological strategies: some leading dimensions of variation between species. Annu Rev Ecol Syst 33:125-159

White PS (1983a) Evidence that temperate east north-American evergreen woody plants follow Corner's rules. New Phytol 95:139145

White PS (1983b) Corner's rules in eastern deciduous trees-allometry and its implications for the adaptive architecture of trees. Bull Torrey Bot Club 110:203-212

Wright IJ et al (2004) The world-wide leaf economics spectrum. Nature 428:821-827 